\title{
Práticas de higiene em uma fei ra livre da cidade de Salvador (BA)
}

\author{
Hygiene practices in a street market \\ in the city of Salvador, Bahia State
}

Ana Cláudia de Sá Teles M innaert ${ }^{1}$

M aria do Carmo Soares Freitas ${ }^{2}$

\footnotetext{
${ }^{1}$ A gência $\mathrm{N}$ acional de Vigilância Sanitária. Av. da Franças/n, Comércio. 40010-000 Salvador BA. venegeroles@yahoo.com ${ }^{2}$ Departamento deCiência da Nutrição, U niversidade Federal da Bahia.
}

Abstract Themain objective of this research isto understand the meaning of the practices concerning food hygiene in a street market in Salvador, the capital of Bahia State in Brazil. The ethnographic study presents two main categories for symbolic production related to hygiene practices: cleanlinessasorder and dirtinessasdisorder. These cultural codes makecorrespondencewith thestudies of $\mathrm{M}$ ary Douglas and $\mathrm{N}$ obert Elias. The codes present particularities to decode everyday life, in which concept and hygiene practices are aspects normalized, in daily activity, for persons who share the space of street market: vendors, consumers, street cleaners and official inspectors. The techno-scientific knowledge and sanitary legislation are strange to the symbolic system of street market vendors. Thelaws areineffectiveand their influence is of little importance in the creation of hygi ene practices. O fficial inspectors' attitudesare coercive and punitive and do not take into account any cultural values when enforcing new hygiene practices.

Key words Hygiene, Hygiene practices, Inspection, Street market, Sanitary surveillance
Resumo Trata-se decompreender os significados das práticas de higiene dosalimentos em uma feira livre da cidade de Salvador (BA). 0 estudo etnográfico consegueapreender duas categoriascentrais como produção simbólica das práticas higiênicas: o limpo como ordem e o sujo como desordem. Esses códi gos culturais fazem correspondências com os estudos de M ary Douglas e N orbert Elias e apresentam especificidades para decifrar um mundo cotidiano em que concepções e práticas de higi ene são aspectos normalizados por personagens que compartilham o espaço da fei ra: feirantes, consumidores, garis e fiscais municipais. O conhecimento técnico-científico e a legislação sanitária são ti dos como estranhosao sistema simbólico dos feirantes. As leis não são efetivas e não têm uma influência importantena construção das práticas higiênicas. As práticas dos fiscais munici pais são coercitivas e punitivas e não consideram os valores culturais na formação de novas práticas de higiene.

Palavras-chave Higiene, Práticas dehigiene, Feira livre, Fiscalização, Vigilância sanitária 
Introdução

Salvador tem uma população estimada em três milhões de habitantes. A taxa de desemprego do município é $22 \%{ }^{1}$ da população economicamente ativa, o que impacta diretamente no crescimento do setor informal. As insuficientes políticas públicas se traduzem nas condições de exclusão social da cidade e produzem efeitos no modo de viver e em aspectos da vida cotidiana. Os baixos salários, as habitações insalubres, os precários serviços saúde e saneamento básico são alguns dos motivos que mantêm distintos val ores culturaissobrea higiene do meio ambiente, objeto central deste estudo. Em particular, a higiene dos alimentos, na feira livre, éuma aquisição histórica e cultural que este estudo busca compreender.

Esta pesquisa mostra como os agentes sociais de uma feira livre da cidade de Sal vador concebem categorias relacionadas à higiene dos alimentos, em que limpo e sujo são símbolos culturais nem sempre associados aos conceitos técnico-científicos. N esse sentido, saberes e práticas higiênicas refletem realidades distintas queseconfrontam, a todo o momento, com valores esistemas simbólicos particularizados em seus contextos socioculturais. Para trabal hadores da feira, consumidores e inspetores sanitários entre vistados neste estudo, há diferentes códigos sobre os campos sanitários.

As práticas higiênicas refletem hábitos que se instituem como códigos socioculturais e as mudanças podem significar mais que a alteração de práticas comportamentais. As concepções sobre limpo e sujo, em geral, estão cercadas de símbolos que refletem saberes de uma cultura própria de quem vive, sobretudo, em precárias condições materiais.

Elias ${ }^{2}$ salienta que, no 0 cidente, desdemuito, os processos de disciplinarização dos corpos, como as regras de higiene, são práticas de refinamento que se diferenciavam nas classes sociais. As sensações do corpo são adestradas a partir de códigos culturais, valores sociais que garantem a inserção do indivíduo em determinado grupo social. Cada grupo, com suas formas específicas de lidar com o corpo, transmite para as gerações subsequentes valores culturais e de classe 3 .

Enquanto sistema de val ores, o que é habitual em uma feira livre se constitui como um produto da estruturas objetivas e subjetivas de seus personagens sobre o modo de ser e pensar o seu cotidiano do trabal ho, a sua sobrevivência nesse ambiente. As ações dos protagonistas desse espaço se revelam relacionadas com suas capacidades cria- tivas que tornam natural as suas condições de vida e geram conhecimentos práticos em seu mundo cotidiano. Trata-se de uma relação ontológica com o mundo, a partir das experiências acumuladas do passado e do presente. 0 habitus higiênico representa o modo como a feira se estrutura para manter comerciantes e moradores do bairro em duráveis correspondências4.

\section{A feira do Japão}

Entre as oito feiras livres do município de Salvador, a feira do Japão foi escolhida como universo de estudo. M eu primeiro contato com esse espaço deu-se em 1999, durante o período do carnaval quando, iniciante na Vigilância Sanitária, fui atuar como fiscal de controle sanitário.

Como profissional de saúde, ao chegar ao local, o que me chamou a atenção foram as suas precárias condições dehigiene. Água suja escorria pelas calçadas e se acumulava na rua, animais se misturavam com pessoas que circulavam naquela via estreita, onde os alimentos eram expostos no chão, em cima de tábuas, plásticos ou jornais.

Esse espaço de conversa e proximidades começou a me atrair e me fez sentir inter essada em penetrar nesse ambiente tão peculiar, onde pessoas traziam seus produtos, suas histórias, suas vidas, suas dores.

Pouco a pouco, com a convivência nessa feira, meu olhar fiscalizador de controladora sanitária foi sendo substituído por outro: o olhar de pesquisadora.

Inicialmente, a minha presença na feira causou certa estranheza, mas no processo em que fui desvendando os códigos do lugar, deixei de ser vista como a "estrangeira". Ao compreender os códigos desse mundo e ao compartilhá-los com os demais atores, passei de visitante à frequentadora. Como diz Da M atta5, saí da sala de visitas e adentrei na intimidade desta casa.

A feira do Japão é considerada uma feira de médio porte, formada por pequenos comerciantes de alimentos, que têm nestetipo decomércio sua subsistência, e serve de apoio aos moradores locais. Lugar de passagem e convívio, ela faz parte da vida dos moradores da Liberdade, um bairro com predominância de grupos sociais de baixa renda.

Muitos feirantes e consumidores moram na mesma rua onde se localiza a feira. A rua é tida como um prolongamento das casas. $\mathrm{Na}$ feira, esses dois mundos se fundem e perdem os limites que os separam. 
Segundo registros da Secretaria M unicipal de Serviços Públicos, órgão municipal responsável pelo ordenamento e fiscalização das fei ras livres do município, erelato do presidente do Sindicato dos Feirantes, a feira do Japão nasceu há 48 anos, num largo situado no início da Rua Gonçalo Coelho, conhecido como Largo do Japão, a partir de um grupo de japoneses que na década de sessenta montava feiras ambulantes em diversos pontos da cidade.

Atualmente, poucos os são os feirantes que têm conhecimento dessa origem; muitos deles associam o nome feira do Japão a uma metáfora que significaria a distância do bairro em relação ao centro da cidade, como um sentido de distanciamento, isolamento.

\section{Procedimentos metodológicos}

0 estudo éum exercício etnográfico sobrea higiene dos al imentos da feira e conta com a análise das narrativas dos agentes que convivem e vigiam o lugar. Nesse universo, circulam feirantes, consumidores, garis que são ligados à Empresa de Limpeza U rbana e são responsáveis pela limpeza do local; fiscais de controle sanitário da Vigilância Sanitária ( $V$ isa), responsáveis pela fiscalização das condições higiênico-sanitárias do comércio e armazenamento dos alimentos, saneantes e cosméticos; e agentes de fiscalização do meio ambiente e serviços públicos da Secretaria Municipal de Serviços Públicos (SESP), responsáveis pelo ordenamento e uso do espaço público. Esses atores foram os interlocutores principais deste estudo.

Com a observação participante, foi possível conhecer códigos socioculturais como qualidade, o que ébom ou ruim para comer, os cheiros, impressões, aspectose particularidades que guardam as relações com a feira. Por meio de entrevistas semiestruturadas e registro de cenas do cotidiano, surgem as categorias mais relevantes do estudo: limpo, sujo, higiene. A leitura de documentos oficiais da vigilância sanitária permitiu compreender como esse sistema interage e se relaciona para manter a resistência em mudar hábitos e a formação de novos.

$O$ projeto queoriginou essetrabal ho foi aprovado pelo Comitê de Ética em Pesquisa do Instituto de Saúde Coletiva da Universidade Federal da Bahia.
Sujo e limpo

para feir rantes e consumidores

O quesignificaria o limpo e o sujo para aquelas pessoas?

Você quer saber o que eu acho fora do comum?

Foi essa expressão que ouvi de uma feirante, quando indaguei sobre a higiene da feira.

Nos discursosacolhidos, a noção de sujo está associada ao que é percebido pelos sentidos do olfato, da visão, do tato e traduz a perturbação da ordem do lugar. 0 mau cheiro, a água que escorre de córregos da rua, o lixo espal hado são situações comuns em que os personagens da feira estão habituados a conviver. Por isso, a retirada do lixo e da sujeira não significa um afastamento do perigo à saúde.

Como você percebe se um lugar está limpo?

0 que eu acho fora do comum não está limpo. (feirante de carne bovina)

A desordem da organização social, a falta de um ordenamento habitual é o que produz incômodo aos personagens acostumados nessas precárias condições de sobrevivência e trabal ho.

Para os comerciantes, o mais importante é manter a organização dos produtos, enfileirados como vitrines para a venda; os folhosos estão ao lado dos temperos, os cereais ordenados em sacos próximos aos ol hares que vigiam a mercadoria enquanto negociam com o consumidor.

No mesmo lugar, os consumidores entendem a lama do chão como sujeira. Para outros, feira e lama estão no mesmo campo semântico em que não há feira sem lama. Os sentidos se mesclam e rompem os limites, circulam livremente, invadindo fronteiras simbólicas. Para os feirantes, a lama pode significar vida, comércio, movimento. Lama é mistura de terra e água e, ao definir feira como lama, se expressa a compreensão da feira como lugar onde pessoas e objetos se misturam. As regi ões associadas à lama se caracterizam como espaços periféricos escondidos, locais de transição: limítrofes em que a presença conjunta da terra e da água demarca um espaço ambíguo ${ }^{6}$. Como a lama, a feira tem sua fluidez.

Para D ouglas ${ }^{7}$, as regras de higiene evoluem à medida que seincorporam novos conhecimentos técnico-científicos. Desse modo, a concepção sobresujo nafeira do Japão refletea interferência da norma científica para al guns feirantes. Eles que nos falam de sujo como presença de bactérias. Para eles, as bactérias são os morotós (larvas de moscas) que, em oposição às moscas, que fazem parte do contexto da feira e não são percebidos como interferência na ordem do ambiente, mas 
incorporados; os morotós simbolizam a sujeira e se associam aos humores corrompidos, que saem das entranhas e invadem o ambiente externo.

Segundo essa autora ${ }^{6}$, "os vermes dizem respeito ao reino da sepultura, da morte e do caos". Simbolizam putrefação, estado de decomposição, não pertencem, portanto, ao ambiente dos vivos, como a feira que requer produtos frescos, símbolos da vida e da saúde. A reflexão sobre impureza pressupõe uma relação entre vida e morte, ordem e desordem.

Entre os feirantes, alguns associam o termo limpeza à virtude, um traço da personalidade, quediferencia e conferestatus dentro do seu universo: Limpeza é uma qualidade da pessoa concedida por D eus. ( feirante de pescado)

A pessoa limpa se distingue moral e socialmente do desordeiro. 0 termo não faz relação exclusiva com a saúde. $E$, ao serem questionados sobre a higiene, muitos consideram esse termo como sinônimo delimpeza do corpo. Assim como limpo, a categoria higiene é identificada como uma característica do modo de ser da pessoa, como conduta moral.

Cada sistema cultural possui códigos de pureza estabelecidos pela distinção entre privado e público ${ }^{7}$. As implicações sobre isto são observadas na feira, em que a rua, o espaço público e a banca do comerciante, o espaço privado, possuem distintas concepções para as práticas higiênicas. 0 sujo está situado no espaço público queé compartilhado com outros; e o limpo, no espaço do sujeito, seu corpo, sua barraca.

Black ${ }^{8}$, em seu estudo etnográfico na feira de Turin, Itália, observa que os consumidores repelem tudo que desconhecem. 0 medo da contaminação e da sujei ra pode al gumas vezes ser interpretado como o medo pelo "outro".

$\mathrm{Na}$ feira, a idéia de limpeza está associada à concepção denormalidade. Para o feirante de pei$x e s$, as escamas no chão, em torno de sua banca, com cheiros fortes, não simbolizam sujeira, mas os restos de vegetais e ossos no chão próximos ao seu trabalho é que indicam o local sujo. Limpo e sujo têm lugares particularizados pelos feirantes com suas mercadorias. Assim, para eles, lugar de peixe tem escamas no chão, lugar de verduras e frutas tem cascas, lugar de carnes, ossos. Isto não representa sujeira, nem desordem.

Para os consumidores desse espaço, a higiene é responsabilidade de todos e não uma característica pessoal dedeterminados sujeitos. A qualidade dos alimentos não está associada às suas condi ções de conservação e sim às características detectáveis, principalmente pela imagem e pelo cheiro do produto. Esses sentidos funcionam como signos das práticas de higiene e se relacionam a outros códigos da linguagem.

Douglas ${ }^{7}$ diz que, quando uma criança aprende determinado código linguístico, ela passa a perceber a linguagem a partir de um ponto de vista particular. Assim, os códigos da feira vão se perpetuando em cada feirante e em seus filhos, sendo interpretados por el es e acrescidos de novos códigos e saberes. N essa perspectiva, quando a feirante M aria diz aos seus filhos que eles devem tratar a farinha de carimã (massa azeda de mandioca, mole, reduzida a bolos secos ao sol) com educação, pois ela não gosta de sujeira, seus filhos vão internalizando os termos "educação" e"sujeira" como opostos. A "educação" para eles representa algo positivo que se deve ter no trato com os alimentos e a "sujeira", como um desagravo. Se essas crianças vão para a escola formal e aprendem outros significados para esses termos, incorporam novas interpretações e constroem seu próprio sistema de códigos. Também, o feirante Gilmário classifica as doenças transmitidas pel os al imentos como "gripe".' Essa interpretação fala da ameaça mais próxima de seu cotidiano.

Para analisar os significados das práticas higiênicas, énecessário penetrar no mundo cotidiano, observar esentir a linguagem, os códigos da linguagem. Os significados estão no campo da experiência, no repertório mesmo da gramática que os representa.

\section{A higiene para os funcionários municipais}

Os símbolos e os sistemas de códigos sobre a higiene são objetos da realidade no mundo do trabalho dos fiscais de controle sanitário, agentes de fiscalização do meio ambiente egaris. Para eles, a sujeira é presente e interfere na ordem do ambiente. Segundo Douglas", "quando tivermos abstraído a patogenia ea higiene das nossas idéias sobre a impureza, ficaremos com a vel ha definição nas mãos: qualquer coisa que não está no seu lugar".

O sujo, antes mesmo de ser considerado orgânico e patogênico, éde ordem simbólica e classificatória. Varrer e lavar são as ações que colocam as coisas em seus devidos lugares. Para os garis, cujo papel central é retirar a sujeira do ambientee trazer a ordem de volta ao local, o termo sujeira significa bagunça, desordem, perigo.

Nos discursos dos fiscais da Vigilância Sanitária, a interferência do conhecimento técnico-ci- 
entífico na sua compreensão sobre limpo e sujo é mais evidente. $N$ as falas desse grupo, o perigo invisível dos microorganismos é traduzido como ameaçadeinsetos, mofo, vetores, veículos dedoenças. Somente os fiscais municipais associam o sangue das carnes expostas à venda à idéia de sujeira e contaminação. Para outros, o sangue faz parte desses espaços na feira, não faz mal. Um gari diz que a sujeira do bairro é diferente da feira. Cada lugar tem sua própria condição higiênica em que as sensações se assemelham ou se afastam.

0 lixo éuma questão cultural em que se notifica a partir de símbolos individuais; o que é lixo para um, pode não ser para outros, dependendo da utilidade que ainda tiver para determinados indivíduos. Os ossos após a retirada da carne podem ser considerados lixo para uns e alimentos para outros.

Na sociedadeindustrial, há doistipos de lixo, o orgânico - lixo por excelência e que causa horror pelo que evoca de morte e tanatomorfose - e o lixo inventado pela sociedade industrial, que é vida sem morte, que não volta às origens, se acumula e causa destruição: são plásticos, vidros, latas. Separamos o lixo que ameaça e pode produzir enfermidades do outro menos sujo $0^{9}$.

Para Douglas 6 , o corpo social configura o modo como o corpo físico é percebido. A limpeza, muitas vezes, indica mais queo cuidado com a higiene, é um cuidado estético, cujo foco éa aparência, antes mesmo de ser a higiene. $\mathrm{N}$ a feira do Japão, o significado de limpo para fiscais municipais reflete o papel que eles desempenham na sociedade e a percepção de si nesse processo social. Enquanto isso, um gari expressa que a limpeza faz as pessoas se sentirem bem, dá uma sensação de bem-estar, segurança, ordenamento.

As referências dos garis (funcionários da prefeitura oficialmenteresponsáveis pela limpeza das ruas) sobre a noção de limpo estão associadas às práticas dessa categoria de trabalhadores. Limpar é colocar as coisas em ordem, organizar, re tirar o que afeta a ordem, o que é estranho ao ambiente. N esse ponto de vista, as ações de limpeza são simplesmente a retirada da sujeira.

Para os fiscais municipais, limpeza é assepsia do espaço. Para um deles, o shopping center simboliza organização e formalidade, palavras que, para ele, estão associadas à limpeza. Vigarello ${ }^{10}$ cita que a limpeza é um fator que distingue as classes sociais; muitas vezes, o termo está associado à urbanidade, ao processo civilizador, numa conotação socialmente distinta. A partir dessas compreensões, observa-se na feira do Japão que a higiene, mais do queum reflexo da vivência dos indivíduos, denota um sistema de símbolos compartilhados pelos atores que vivenciam o lugar.

Luckmann e Berger ${ }^{11}$ frisam que a construção do nosso sistema simbólico tem origem nos processos de reflexão subjetiva, "os quais, depois da objetivação social, conduzem ao estabelecimento deligações explícitas entre os temas significativos que têm suas raízes nas várias instituições". Assim, a forma como o indivíduo cuida dos alimentos éresultado da sua história, do que aprendeu com seus pais, familiares e amigos, na escola, no cotidiano do trabalho. Para os profissionais, cuja ação interfere diretamente nas práticas de higiene, éimprescindível compreender a rede de significados dessas práticas, formalizadas num tempo eespaço definidos, como o exemplo da feira. Essa compreensão pode subsidiar o processo de educar sem a necessidade de formas punitivas.

A intervenção dos fiscais se configura como a imposição de normas sanitárias em que se categorizam os feirantes. Ao lembrar estudos de Foucault ${ }^{12}$ sobre o poder, entende-se que os fiscais mantêm uma relação de vigília e controle sobre 0 comportamento sanitário dos feirantes para a regularidade de uma homogeneidade do ambiente, sem qualquer pré-compreensão das questões que envolvem o lugar. Para os fiscais, fiscalização emulta ocupam seusinteresses na disciplinaridadedosfeirantes, impondo limites e comportamentos.

A norma sanitária utilizada como instrumento de disciplina gera no imaginário do feirante a crença de que a higiene é um saber específico de doutores. Saber e poder mesclam-se na feira entre os personagens que compram, vendem, limpam efiscalizam. Em nome da higienização, fiscais controlam os indivíduos. E, ao conceberem a higiene como algo formalizado, eles a afastam do senso comum. Assim, ela pertence à ciência ou ao saber formal dos técnicos.

A higienedistingue classes sociais, separa grupos entre os que possuem saber e os que não possuem. Segundo Foucault ${ }^{13}$, a norma como um corpo deleis não diferencia situações eimpõe a oposição binária entre o permitido e o proibido. Por meio da normalização pela disciplina, corrigem-se comportamentos desviantes. Essas são as referências conceituais dos fiscais cuja tentativa discursiva para homogeneizar a feira énegada pel os comerciantes que entendem a fiscalização como policiamento e repressão. 


\section{Consideraçõesfinais}

A prática de compra evenda de al imentos ocupa funções culturais desses agentes sociais, cujas falas são ressignificadas para mostrar a relação entrealimentos, trabal hadores, feirantese demais personagens da feira. Cada sujeito, com sua história, significa a higienee as práticas apropriadas de um saber comum. Entre os distintos atores que circulam na feira do Japão, o limpo e o sujo são as categorias principais que se associam ao caráter estético enão, necessariamente, ao cuidado com a saúde.

As racionalidades sobre os riscos para a saúde geram uma estrutura, uma concepção, um arranjo, uma ordenação da feira que afeta a tradição, as crenças e interfere na significação da higiene como uma prática social. No código cultural da feira, o familiar e o estranho justificam as práticas de higiene e sustentam as noções sobre sujo elimpo. A sujeira éestranha porque não pertence ao ambiente. 0 limpo é o familiar, 0 reconhecido epertencente ao feirante.

0 enfoque sobre a limpeza tem duas situações: o limpo vem de dentro da pessoa, para a ordenação do mundo cotidiano. Em outro momento, o sentido vem de fora da feira, efeito do poder da fiscalização e da multa. A limpeza é, então, polissêmica, significa asseado, tratamento pessoal, educação, ordem e cada coisa em seu devido lugar.

Para muitos feirantes, o sujo está no outro e não em si. O limpo éatribuído ao lugar comum e o impuro, ao incomum. De outro modo, os que pensam a idealidade da norma não entendem as construções socioculturais e punem. Feira, lugar de bagunça, desordenado são alguns termos que se assemelham para o fiscal. Para o fei rante, feira é liberdade, afetividade, conciliação; e para os funcionários municipais, a informalidade da feira afeta a saúde.

A sujeira da feira enunciada por fiscais representa mais que a presença de sujidade. Para eles, a sujeira é a própria feira, pois ela está fora do seu sistema de classificação, da ordem que a lei estabelece para as coisas. Desse modo, limpar a feira significa acabar com a sua característica de informalidade, dando ordem ao lugar, padronizando não apenas as barracas, mas as formas de comportamento.

Para os fiscais, a feira éum espaço que agride seu senso estético; éabominável (fala deum fiscal da Visa) e deve ser extinta. Ao negar o reconhecimento de seu próprio objeto de trabalho, também não sesente valorizado. A pesar de alei asse- gurar que a comercialização ea exposição de alimentos in natura para o consumo humano só serão permitidas com prévia autorização por órgãos competentes, apesar dos critérios sanitários que tentam assegurar condições de conservação, higiene, limpeza e proteção do alimento, na compreensão das autoridades sanitárias, a feira não faz parte de seu foco de ação formal, pois é categorizada como uma atividade do comércio informal.

Feirantes e consumidores desse universo reproduzem em suas falas a sua compreensão das categorias analisadas, com base na sua vivência e na forma como interpretam as informações que Ihes são passadas em cursos ministrados por agentes do governo ou diretamentedurantea fiscalização na feira. Essas informações são compreendidas a partir de códigos que utilizam para interpretar os fenômenos de sua realidade.

O saber popular é um saber fragmentado entrea tradição ea apreensão do novo; eleéconstituído por fragmentos que as classes populares conseguem absorver das informações da mídia, dos fiscais e das classes mais abastadas. Assim, 0 saber se constrói e se molda ao cotidiano como uma adaptação à ordem referencial. Conforme narrativas dos feirantes, o que eles sabem sobre seu ofício e a forma de lidar com os alimentos foram aprendidos com seus pais, como conhecimentos herdados que vão se incorporando no habitus 4 feirante. N esse contexto, as práticas habituais de higiene, mais que práticas herdadas e transmitidas por gerações de feirantes, são frutos da recodificação feita por eles e, por vezes, das normas que lhes são impostas. Ainda assim, normas, cursos esporádicos ofer ecidos por agentes do governo, ações coercitivas de fiscalização e controletêm pouca influência na construção das práticas higiênicas.

Também, conforme nossa observação, a limpeza do lugar é utilizada como estratégia de marketing e não como um aspecto da saúde. Para eles, deve-se manter a limpeza, conforme a demanda dos fiscais, para atrair fregueses e não porque a falta de higiene contamina o alimento e provoca doenças. Em outras palavras, a idéiacentral de contaminação está associada à alteração estética do produto e não à presença de um contaminante, seja ele físico, químico ou biológico, conforme o discurso técnico-científico. No dia a dia desses homens e mulheres, 0 alimento éfonte de renda para matar a fome e esse lugar nomeado feira é encontro, parentesco e conversas.

As práticas dosfiscais municipais não são educativas, mas coercitivas e punitivas, em busca de 
uma ordenação que não leva em consideração o senso comum enquanto pano de fundo para a formação das práticas de higiene. São imposições do discurso oficial e não são eficazes na construção das práticas dos sujeitos. Os feirantes da feira do Japão são atores e atrizes ativos, inseridos em suas realidades, detentores de conhecimento e práticas próprias, constituintes do habitus ${ }^{4}$ feirante que vem se construindo desde muito.

É impossível pensar em qualquer mudança de comportamento sem pensar em mudança de signos. Para intervir nas práticas de higiene, os profissionais de saúde devem se inteirar dos códigos que compõem a cena e seus personagens.

A correspondência entre os significantes das falas desses agentes sociais traz resultados que justificam a necessidade de mudanças da prática disciplinar sanitária. Não será a punição a reverter códigos, conceitos, estruturas, mas, antes, a observância dos valores culturais sobre a feira e sua estética que irá definir a higiene dos alimentos e a saúde.

A história da higiene na feira é construída no processo de configuração das práticas dos diversos atores desse espaço, movendo-se entre a tradição e os novos saberes de suas realidades de feirantes, garis, fiscaise consumidores. 0 queleva os feirantes a significarem suas condições de higieneestá relacionado ao contexto socioeconômico em que vivem e seus habitus ${ }^{4}$. Esses têm suas raízes no conhecimento que vai passando de geração em geração e pouco a pouco se transformando na história inscrita no corpo desses atores4.

Com base nessas considerações, compreendemos que as práticas de higiene são formadas a partir da interação de diversos sistemas simbólicos, em que os saberes se mesclam e se dividem entre o êmico e o ético, o popular, tradicional eo técnico-científico. Convive-se com o estranho e o familiar, a norma e outros códigos. A feira é um espaço designificações quenecessita ser compreendido para que as intervenções sanitárias se viabilizem. E isto só é possível pela via dialógica entre os distintos saberes e práticas.

Os feirantes sentem os efeitos do poder da lei, tentam modificar ou não suas práticas populares dehigienee mantêm as repostas representacionais de sua condição humana, em seu lugar, o mundo da feira, para sentir sua identidade sociocultural. As respostas estão na prática, com os acordos nem sempredizíveis, entreas pessoas desta cena diáriae antiga, a feira do Japão, na Liberdade da Bahia.

\section{Colaboradores}

ACST M innaert elaborou o projeto de pesquisa, coletou eanalisou os dados que serviram de base para este artigo e M CS Freitas participou da concepção do projeto queoriginou o artigo eda análise dos dados. Todos os autores participaram da elaboração e revisão deste texto.

\section{Agradecimentos}

A realização desta pesquisa contou com apoio financeiro da Agência Nacional deVigilância Sanitária, através do Centro Colaborador em Vigilância Sanitária do Instituto de Saúde Coletiva da Universidade Federal da Bahia. 


\section{Referências}

1. Superintendência de Estudos Econômicos e Sociais da Bahia. Pesquisa de Emprego e Desemprego na Região M etropolitana de Salvador 06/2007. [site da Internet] [acessado 2007 ago 15]. Disponível em: http://www.sei.ba.gov.br

2. Elias N. O processo civilizador: uma história dos costumes. Vol. 1. Rio de Janeiro: Zahar; 1994.

3. Mauss M. 0 ensaio sobre a dádiva. São Paulo: Ed. Universidade de São Paulo; 1974.

4. Bourdieu P. 0 poder simbólico. Rio de Janeiro: Bertrand Brasil; 2002.

5. Da Matta R. A casa e a rua: espaço, cidadania, muIher e morte no Brasil. Rio de Janeiro: Rocco; 1997.

6. Douglas M. Pureza e perigo. Lisboa: Edições 70; 1991.

7. Douglas M. Natural Symbols. London: Routledge; 2003.

8. Black RE. The Porta Palazzo Farmer's Market. Anthropology of Food, 04. [site da Internet] [acessado 2006 jan 06]. Disponível em: http://www. aofood.org/Jounall ssue/04/ede.pdf

9. Rodrigues JC. Higiene é ilusão. Rio de Janeiro: Nau; 1995.

10. Vigarello G. 0 limpo e o sujo: uma história da higie ne corporal. São Paulo: M artins Fontes; 1996.

11. Luckmann T, Berger PL. A construção social da realidade: tratado de sociologia do conhecimento. Petrópolis: Vozes; 1998.

12. Foucault M. Microfísica do poder. Rio de Janeiro: Graal; 1979.

13. Foucault M. Vigiar e punir. Petropólis: Vozes; 1999.

Artigo apresentado em 23/11/2007

Aprovado em 11/01/2008

Versão final apresentada em 02/04/2008 